\title{
TRADUÇÃO \\ O lugar de Kepler na história intelectual europeia ${ }^{1}$
}

Ernst Cassirer

Na apologia de Tycho Brahe, em que Kepler se coloca em posição antagônica a Reimarus Ursus, matemático imperial na corte de Praga, exprime-se, em proposições concisas e características, sua visão geral da essência da astronomia e da "ideia de astrônomo". O astrônomo verdadeiramente perfeito não deveria se limitar a observar os fenômenos e, com base nessas observações, prever os futuros eventos celestes.

Aquele que prediz os movimentos e as posições dos astros, da forma mais perfeita possível, cumpre sua obrigação como astrônomo. Entretanto, aquele que, para além disso, estabelece proposições verdadeiras sobre a forma do cosmo, realiza algo ainda mais sublime e merece os maiores elogios. Assim, alcança a verdade, desde que ela seja sensivelmente apreensível; através de suas conclusões satisfaz não apenas o sentido da visão, mas revela também a essência mais profunda da natureza. (...) portanto, o astrônomo não deve ser deixado de fora da comunidade dos filósofos que investigam a natureza das coisas (Kepler, 1858, p. 242).

Com essas palavras, escritas por Kepler aos seus trinta anos, delineou-se o tema fundamental que desde então permeou toda sua vida e seu trabalho científico: "não há (...) astrônomos do grupo dos filósofos que investigam excluindo a natureza" (idem, ibidem). Em suas cartas, repete-se sempre a seguinte reivindicação: não se deve condená-lo ao mero aperfeiçoamento dos cálculos matemáticos, mas concederlhe tempo e ócio para dedicar-se às suas especulações filosóficas, que são sua maior felicidade. "Outros podem se contentar com o mero cálculo; o que me cativa é a florescência da astronomia, a disposição em conformidade com princípios e a beleza dos movimentos". ${ }^{2}$ Deveras, palavras como essas, não são proferidas com base na

1 Publicado originalmente como: Cassirer, E. (1930). Keplers Stellung in der Geschichte der europäischen Geistesgeschichte. Verhandlungen des naturwissenschaftlichen Vereins in Hamburg, 4 (3-4), pp. 135-147. Tradução de Serzenando Alves Vieira Neto (doutorando na Universidade Estadual de Campinas). Neste texto Cassirer apresenta a dimensão filosófica do processo de transição da antiga concepção tardo-medieval da astrologia, para a moderna concepção de astronomia. Esse processo, que assume na obra de Johannes Kepler seu ponto auge, é investigado em seu íntimo diálogo com a tradição filosófica e científica, apontando, precisamente, para os elementos mais gerais que indicam uma nova forma da compreensão de mundo, o entendimento como o próprio artífice da natureza. Embora se encontre entre seus textos de menor repercussão, $O$ lugar de Kepler na história intelectual europeia se apresenta como um rico exemplo de seu interesse pelo tema da transição para a modernidade e pelo tema do pensamento místico-astrológico, reflexo direto de seu contato com comunidade intelectual de Hamburgo, sobretudo, com a Bibliothek Warburg. (Nota do Tradutor)

2 Carta de Kepler a Vinzenz Bianchi de 17 de fevereiro de 1619. 
subestimação da importância do cálculo matemático. Talvez, em toda história da astronomia, não tenha existido alguém dedicado ao cálculo, de forma tão infatigável e persistente, tão apaixonada e entusiástica, como Kepler. Porém, para Kepler, o cálculo constitui sempre um ponto de partida e de reflexão; o escopo, ao qual se aspira, não se assenta no cálculo em si mesmo, mas na formação da teoria, à qual ele conduz. Em contrapartida, para Kepler, a teoria científica era essencialmente atrelada e inseparável da filosofia. Uma das mais importantes realizações de Kepler no âmbito da história intelectual europeia assenta-se sobre esse estrito direcionamento filosófico. Ele não chegou a novos conhecimentos dentro de uma teoria existente. 0 produto primordial de seu trabalho intelectual consiste no fato de estar entre os fundadores e entre os mais enfáticos promotores da própria ideia de teoria científica, no fato de ser um dos primeiros a contemplar essa ideia de forma clara, demostrando e assegurando sua possibilidade.

Basta um olhar sobre o lugar histórico da teoria de Kepler para deixar esse seu traço essencial em evidência. A conformação da astronomia antiga partia da visão fundamental de que a Terra se encontrava imóvel no centro do universo e de que os corpos celestes orbitavam ao seu redor em círculos perfeitos. A linha do círculo vale aqui como a forma necessária do movimento; pois, o círculo é sozinho a figura perfeita, porque nele, e somente nele, conserva-se o mais alto ideal da simetria. Toda a física aristotélica se baseava sobre esse pressuposto, sobre a ideia de que a eterna substância imutável dos corpos celestes deveria conservar a máxima da simetria interior, que se expressa na linha do círculo. Também em Copérnico, essa visão permanece essencialmente inalterada. Outro movimento dos corpos celestes, diferente da órbita perfeita, como ele expressamente explica, seria indigno dessa mais nobre e sublime composição da natureza. E, com isso, apresenta-se outra suposição: o movimento dos astros deve ser rigorosamente uniforme; não deve apresentar, ora maior, ora menor velocidade. Porque a desaceleração da velocidade somente seria explicável a partir de uma desaceleração da força movente - tal desaceleração, no entanto, só existe nos movimentos terrestres e não nos celestes, os quais são colocados em órbita pelo "eterno movente", ${ }^{3}$ de acordo com a visão filosófica básica das inteligências celestes ${ }^{4}$ ainda seguida por Copérnico. Kepler rompeu com ambas as concepções. Substituiu o círculo pela elipse e ensinou que o movimento elíptico se apresenta ora mais rápido, ora mais lento. Segundo Kepler, há uma correspondência totalmente determinada, uma correspondência exata entre a velocidade e a distância em relação ao Sol. As velocidades dos planetas se comportam de forma inversa à distância. Dessa forma, o planeta no periélio (próximo do Sol) se movimenta mais rapidamente, o planeta no afélio (distante do Sol) se movimenta mais lentamente.

3 No original, ewige Beweger. (Nota do Tradutor.)

4 No original, himmelsche Inteligenzen. (Nota do Tradutor) 
Nessa observação se encontrava o embrião da, assim chamada, segunda lei de Kepler, cujo princípio fundamental é o de que os movimentos dos planetas ocorrem de forma que os vetores radiais do Sol em direção aos mesmos varrem, em um mesmo intervalo de tempo, áreas iguais. Com isso, encontrou-se um dos princípios ${ }^{5}$ mais importantes para a configuração da futura astronomia. Todavia, também aqui, tratou-se de mais do que a descoberta de um importante conhecimento particular no âmbito das ciências da natureza. 0 que se consumou com a descoberta de Kepler da forma orbital de Marte foi algo além. Foi uma mudança da mentalidade científica e filosófica. Podese exprimir concisamente essa mudança quando se diz que Kepler foi o primeiro a se arriscar na transição da unidade da figura para a unidade da lei, ${ }^{6}$ que constitui, em cada formação unitária, o núcleo e o sentido de toda reflexão científica. Isso se evidencia de modo característico, por exemplo, na troca de cartas entre Kepler e Fabricius. Em Praga, Fabricius trabalhou sob Tycho Brahe juntamente com Kepler, investigando a lei do movimento dos planetas. Não obstante, Fabricius não foi capaz de, no conjunto de sua pesquisa, desvincular-se da ideia de que a figura do círculo é o ideal mais alto e a única forma perfeita, o ideal que toda teoria deveria se esforçar para alcançar. Quando esse ideal não é alcançado, não é comprovado como forma definitiva do movimento, na verdade, ainda não se penetrou no fundamento, de fato, da natureza. E, ao mesmo tempo, Fabricius reivindica que todas as irregularidades do movimento, por fim, sejam reduzidas a movimentos puramente uniformes. Contra essa visão, Kepler responde com a tese decisiva, deveras lapidar, segundo a qual a astronomia deveria aspirar à unidade suprema. Essa unidade, genuína e primordial, entretanto, não deveria ser buscada nos próprios movimentos, em sua simetria dimensional ou em sua uniformidade temporal, pelo contrário, deveria ser buscada nos princípios do movimento. A teoria mais perfeita, por conseguinte, seria aquela que depreende dos princípios mais simples possíveis a maior variedade e a maior multiplicidade. Para essa sua perspectiva fundamental, Kepler invoca ninguém menos que Platão: porque a "ideia"7 platônica não é simplesmente a unidade da forma, mas é a unidade do múltiplo e a unidade no múltiplo. Com essa inovação fundamental do princípio da astronomia propiciou-se imediatamente uma nova perspectiva geral, não apenas da construção do universo, mas uma nova interpretação da essência e da tarefa do intelecto científico.

$\mathrm{Na}$ verdade, para o próprio Kepler essa mudança na perspectiva geral não se efetivou de maneira repentina. Foi resultado de um longo e persistente trabalho do pensamento, um trabalho extremamente complexo. Em seu primeiro grande escrito sobre a astronomia, no Mysterium cosmographicum, Kepler ainda se mantém

\footnotetext{
5 No original, Wahrheiten. (Nota do Tradutor)

6 No original, von der Einheit der Gestalt zur Einheit des Gesetzes. (Nota do Tradutor)

7 No original, Idee. (Nota do Tradutor)
} 
inteiramente firme na exigência do rigoroso esquematismo geométrico. 0 universo é constituído segundo um modelo físico - segundo o modelo dos cinco corpos platônicos, como produto base da estereometria. Começa-se pela Terra, descrevendo-a como um dodecaedro. A esfera que abrange esse dodecaedro é a esfera de Marte. Em torno da órbita de Marte coloca-se o tetraedro. Assim, a esfera que abrange esse corpo regular pertence a Júpiter. Atribui-se o cubo a Saturno, o icosaedro a Vênus, o octaedro a Mercúrio. Como se vê, Kepler construiu a partir das formações da estereometria, de certo modo, um modelo físico seguro, a partir do qual o universo se organizava. Entretanto, quanto mais ele avança, mais se distancia desses limites iniciais. Sua imagem do mundo não é mais plástico-geométrica, mas é puro dinamismo; já não nasce da geometria e da estereometria, mas aspira, como ele mesmo expressa, a uma pura "aritmética das forças". E, com isso, foi alcançada uma duplicidade. A hipótese copernicana já havia empreendido a desvinculação da aparência derivada dos sentidos. Kepler enxerga o valor decisivo dessa hipótese precisamente nisto, que o juiz sobre o verdadeiro e o falso, sobre a construção e a ordem do cosmo, não é a aparência derivada dos sentidos, mas o entendimento matemático, a rationes mathematicae. Todavia, Kepler teve que dar um passo além. Para ele, aplica-se não apenas o rompimento com o domínio dos sentidos, mas também com o domínio da intuição e da fantasia intuitiva. A tarefa que aqui se coloca é tão grande e tão complexa, como eram essas duas forças fundamentais que o próprio Kepler, em grande medida, possuía e que definiam, de modo decisivo, a estrutura de todo o seu ser espiritual. Certa vez Goethe disse que não se poderia pensar em nenhum grande estudioso da natureza desprovido de faculdade imaginativa. Esse princípio talvez valha para Kepler mais do que para qualquer outro. Kepler jamais se atém à mera observação dos fatos, ao dado imediato, mas, com audácia inigualável, aponta para cima, para o domínio da possibilidade; associa, na livre fantasia combinatória, os casos possíveis e simplesmente antecipa, com essa fantasia, aquilo que é diretamente observado. Mas, independentemente da intensidade desse impulso da fantasia, Kepler não se deixa levar, ao contrário, conduz e enfrenta sua faculdade da imaginação científica por meio da mais aguda crítica. Esse permanente jogo de mudança da fantasia criativa e do rigoroso entendimento examinador é, talvez, o mais importante e interessante traço da natureza intelectual de Kepler. Ele não apenas praticou essa dupla função, mas estava claramente consciente dela. Na investigação científica, sempre procura por símbolos, alegorias e metáforas. É como se não pudesse viver e falar de outra forma, a não ser através de símbolos; aliás, por outro lado, Kepler encontra-se diante dessa abundância afluente de imagens, que está sendo constantemente recriada de forma clara e cuidadosa. "Eu também jogo com os símbolos", assim disse certa vez em uma carta, 
mas eu jogo de forma a jamais me esquecer de que se trata apenas de um jogo. Pois, exclusivamente por meio dos símbolos nada pode ser demonstrado; a menos que seja comprovado através de fundamentos seguros que eles não são meramente analogias e alegorias, mas que encerram em si uma causalidade autêntica, uma verdadeira ligação causal $^{8}$ (Kepler, 1858, p. 378).

Nesses simples princípios foi descoberto aquele conceito de "causa verdadeira" (vera causa) sobre o qual Newton pôde, mais tarde, assentar seu edifício científicouniversal. Em Kepler, a faculdade imaginativa e a faculdade do entendimento crítico mantêm mutuamente a balança, e a partir de ambas se produz um efetivo equilíbrio ideal, o qual podemos designar, novamente com uma expressão de Goethe, como o poder da "exata fantasia sensível” (Goethe, 1893b, p. 75). Mas, mesmo nesse domínio, Kepler cresce mais uma vez como cientista natural em sua realização efetivamente decisiva, uma vez que ele compreende o conceito de lei natural de modo tão rigoroso e abrangente, arqueando-o tão alto, de forma a visualizar na lei natural uma determinação puramente intelectual que, em princípio, não está mais sujeita aos limites do intuitivo e daquilo que é representável intuitivamente. Kepler deu esse passo em seu tratado sobre as hipóteses, escrito na virada do século XVII como apologia de Tycho Brahe, publicado somente no século XIX, como parte do grande projeto editorial de Frisch. ${ }^{9}$ Esse breve trabalho, escrito por Kepler aos seus trinta anos, contém nada menos do que o prólogo lógico para uma nova astronomia e o programa lógico de uma nova física. Como tal, esse trabalho possui para a história da filosofia ainda hoje um significado simplesmente clássico. Deve-se situá-lo, em sua amplitude interna, diretamente ao lado do Discurso do método de Descartes, cuja publicação se deu mais de uma geração mais tarde. Ainda hoje o lógico pode comentar o sentido e o caráter de suas hipóteses científico-naturais, mas não faz algo melhor do que simplesmente citar os princípios fundamentais de Kepler. Os resultados lógicos de ambos os fundadores da ciência natural moderna se distribuem de tal modo que Galileu pode ser denominado como lógico do experimento e Kepler como lógico da hipótese. Com sua teoria da hipótese, Kepler criou o primeiro instrumento, de fato intelectual, da moderna pesquisa das ciências naturais. Certamente, nos mais de 300 anos que nos separam do trabalho de Kepler, esse instrumento foi essencialmente aperfeiçoado, refinado e aprofundado; mas sua natureza e sua estrutura não foram, com isso, alteradas. A hipótese da física moderna - basta pensar na teoria da relatividade geral e no desenvolvimento mais recente da teoria quântica - defronta-se com o mundo da intuição essencialmente mais livre e arrojado, indo decisivamente muito além do que era possível na época de Kepler. Com efeito, as proposições fundamentais sobre as hipóteses físicas podem ser ainda hoje repetidas por todo cientista natural, da forma como foram ditas por Kepler. Tem-se referido oportunamente à forte analogia existente entre as pesquisas de Kepler e Niels Bohr.

8 Carta de Kepler a Joachim Tanck de 12 de maio de 1608.

9 Christian Frisch (1807-1881) organizou e editou os escritos inéditos de Johannes Kepler em oito volumes, publicados entre 1858 e 1871 . (Nota do Tradutor) 
Como se sabe, Bohr descobriu no microcosmo, no interior da construção atômica, o mesmo princípio indicado por Kepler no macrocosmo, no movimento dos planetas. Sommerfeld, em seu trabalho sobre a Estrutura atômica e as linhas espectrais, ${ }^{10}$ pôde oferecer uma apresentação da teoria de Bohr que demonstrava passo a passo sua contínua correspondência com a teoria dos planetas de Kepler. Certamente, essa analogia não é um fato admirável apenas para o cientista natural, mas é também, em grande medida, capaz de despertar "admiração filosófica". Mas o que se mostra ainda mais admirável para o lógico é a harmonia da convicção metodológica básica que se pode observar em Kepler e em Niels Bohr. "Primeiramente", assim soam as palavras de Kepler,

delineamos em hipóteses uma imagem da natureza das coisas; então realizamos um cálculo com o apoio dessas hipóteses e mostramos os movimentos daí resultantes; e, logo em seguida, os resultados desses cálculos são novamente confrontados e comprovados com base nos fatos observados (Kepler, 1858, p. 244).

Com essas proposições, Kepler fixou as regras básicas gerais de toda a formação da teoria física; regras que se aplicam não menos do que sua teoria dos corpos celestes se aplica ao modelo atômico de Bohr e às conclusões a ele associadas. Kepler descobriu e conquistou com essa disposição do conceito de lei natural - no sentido mais literal da palavra - uma nova dimensão do pensamento. Foi o primeiro a romper com uma concepção básica do universo, na qual toda sua grandiosidade e beleza ainda estavam atreladas aos limites da beleza pura, da configuração plásticoconcreta. Kepler é o primeiro pensador europeu a consumar, com total clareza, a passagem da figura para a lei pura, ${ }^{11}$ a passagem da simetria (que consistia na norma mais sublime da antiga imagem do universo ptolomaico) para a harmonia pura. Não é essa uniformidade que ele vê na linha circular, com a distância igual entre todos os pontos e o centro, que é a mais elevada e a mais alta ordem do pensamento físicoastronômico. Desde então, não é mais a uniformidade de certa forma geométrica que vale como medida a partir da qual o pensamento mede a si mesmo e o mundo, mas a uniformidade de determinados princípios geradores.

$\mathrm{E}$, com isso, novamente se alcança, na evolução geral da história intelectual, algo novo. A obra de Copérnico, De revolutionibus ${ }^{12}$, não representa apenas um marco no desenvolvimento da teoria da natureza. Com ela, encontramo-nos diante de uma verdadeira transição de épocas. Goethe exprime da forma mais bela e expressiva o significado da teoria copernicana.

Talvez nunca tenha existido uma exigência maior à humanidade, tendo em vista que não se passou tudo por um reconhecimento consensual: um segundo paraíso, um

10 Cassirer refere-se a Atombau und Spektrallinien, obra de Arnold Sommerfeld publicada em 1919. (Nota do Tradutor)

11 No original, von der Gestalt zum reinen Gesetz. (Nota do Tradutor)

12 Cassirer refere-se a De revolutionibus orbium coelestium, obra publicada em Nürnberg no ano de 1543. (Nota do Tradutor) 
mundo da inocência, da poesia e da devoção, o testemunho dos sentidos, a convicção de uma crença poético-religiosa; não é de se admirar (...) que tal ensinamento tenha encontrado oposições das mais diversas formas; aquele que o abraçava legitimava e abria as portas para uma liberdade e grandeza do pensamento até então inconcebível, desconhecida (Goethe, 1893a, p. 213).

Kepler foi o primeiro pensador europeu a realizar esse desafio de modo pleno menos limitado pela tradição do que o próprio Copérnico e essencialmente mais claro, agudo e seguro do que Giordano Bruno. A estima pela Bíblia e pela Igreja não mais o atava. "Para mim, Lactâncio", assim diz Kepler,

que negou a forma esférica da Terra é santo; santo é Agostino que admitiu a forma esférica, mas contestou a possibilidade das antípodas; santo é o clero de nossos dias, que reconhece a pequenez da Terra, mas nega seu movimento. Entretanto, para mim, a verdade é mais sagrada, quando demonstro, por meio da pesquisa científica, com todo respeito pela doutrina eclesiástica, que a Terra é redonda, que ela é habitada por antípodas, que ela percorre sua órbita entre os astros na qualidade de um pequeno e insignificante corpo celeste (Kepler, 1860, p. 156).

Assim, Kepler não apenas compreende e avalia a teoria de Copérnico como uma hipótese astronômica, mas como um ato do pensamento que representava imediatamente um ato moral. Com frequência e com deleite, Kepler citava a frase que deveria ter sido o lema de Copérnico: “Quem deseja filosofar deve possuir liberdade de pensamento" (Kepler, 1859, p. 485).

Aos contemporâneos, Kepler parecia, em virtude dessa mentalidade que não se vinculava definitivamente a qualquer regra da tradição, ser simplesmente o aniquilador, o destruidor da mais sagrada veneração. Mas essa destruição era apenas o começo, a condição prévia de uma nova organização. Pode-se aplicar a Kepler, em um sentido totalmente particular, a sentença proferida pelo coro dos gênios diante de Fausto:

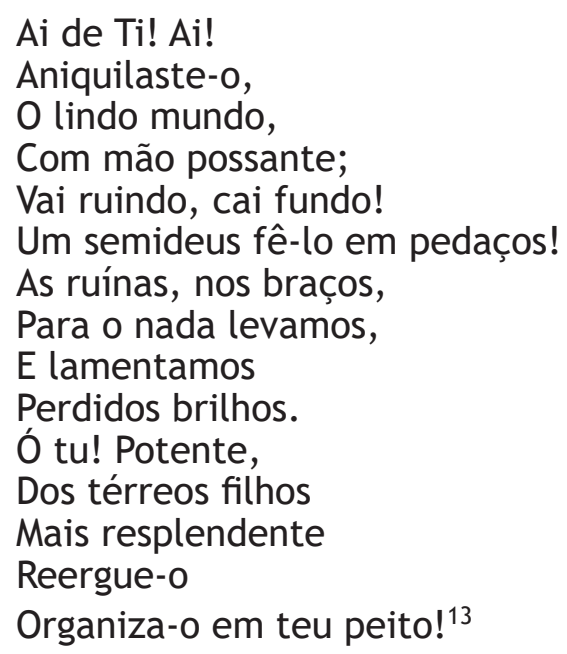

13 Baseado na tradução de Jenny Klabin Segall, com pequenas alterações a fim de conformar a tradução à interrupção da citação. Cf. Goethe, 2011, pp. 136-137. (Nota do Tradutor) 
Essa construção do universo no próprio espírito é o segundo grande feito de Kepler, um feito de caráter genuinamente filosófico. Esse, consuma-se quando Kepler, depois de ter conseguido reconduzir os movimentos do cosmo ao princípio do número e da harmonia, busca, para esses mesmos princípios, novamente um fundamento mais profundo, reconduzindo-o ao espírito como seu centro e fonte primordial. Não existem números e harmonias na qualidade de coisas em si mesmas; eles existem apenas em relação a um espírito capaz de compreendê-los e reencontrá-los em si mesmo, em seu princípio dominante. No espírito divino existe e predomina o número e a harmonia, de forma anterior e mais primordial do que as coisas - a partir daqui comunica-se, por um lado, com o universo físico, por outro, com o espírito humano. Por conseguinte, não é necessário que se encontre exclusivamente pela observação do mundo objetivo e que se aprenda a partir dele; o espírito compreende de maneira mais verdadeira, profunda e primordial se ele retrocede a si mesmo, à sua própria natureza e essência. Mesmo se ao espírito jamais tivesse sido concedida a habilidade de enxergar - assim diz Kepler -, não the faltaria o conhecimento do número e da quantidade, pois isso é originalmente inerente à sua própria capacidade. 0 entendimento puro, que é inato à alma, exige o olho para seu emprego e realização; o olho é de um determinado modo, porque, e até o ponto em que, o espírito é de determinado modo - o oposto não se aplica. Novamente um pensamento com a mais alta audácia idealista; todavia, a evolução da história do conhecimento da natureza demonstrou que somente por meio dessa audácia pôde-se abrir e conquistar o seu domínio mais próprio. Somente através do idealismo platônico de Kepler o realismo da moderna ciência natural pôde se desenvolver. E o idealismo metafísico de Kepler, que encontrou no conceito de Deus sua mais pura expressão e sua mais sublime agudez, assume então, depois de a própria história do conhecimento da natureza entrar em uma nova fase, graças a Kant, outra forma, a forma do idealismo "transcendental" o qual doravante pode ser explicado em um novo sentido e como que com uma nova entonação em seu significado, qual seja, que todas as peculiares leis da natureza são apenas especificações de leis gerais do entendimento e, nesse sentido, o "próprio entendimento é o artífice da natureza" (Kant, 1781, p. 111).

Permitam-me, senhoras e senhores, não tanto concluir minha exposição, mas interrompê-la - já se esgotou o tempo que me foi concedido. Com isso, acredito que muito do que aqui foi indicado e esboçado encontrará seu complemento e aprofundamento nas subsequentes conferências do Prof. Schorr ${ }^{14}$ e do Dr. Schimank. ${ }^{15}$ Permitam-me, para encerrar, dizer ainda algumas palavras sobre um ponto, cuja omissão faria com que a imagem geral do trabalho filosófico de Kepler ficasse incompleta. Trata-se da postura de Kepler diante da astrologia, aquela potência

14 Richard Schorr (1867-1951). (Nota do Tradutor)

15 Hans Schimank (1888-1979). (Nota do Tradutor) 
fundamental que ainda dominava com toda força a ciência do século XVI e de princípios do século XVII e que intervia de modo mais profundo no conjunto do ser espiritual da época. Kepler se encontrava ligado à astrologia da forma mais estreita; seu ofício e posição social, seu cargo como matemático imperial na corte de Rudolf II, ${ }^{16}$ exigiam dele o constante contato e o contínuo estudo da astrologia. Mas, ainda que dessa forma, ao longo de sua vida, ele estivesse conectado em muitos aspectos à astrologia, essa ligação externa jamais representou um vínculo interno, um grilhão intelectual. Kepler elaborou um grande número de prognósticos e calculou muitas natividades ${ }^{17}$ - todavia, a astrologia jamais se transformou em um fator determinante de seu destino intelectual. De forma ousada e consciente, contrapunha a crença no destino astrológico à crença no engenho científico; seus astros não eram Marte e Saturno - assim disse certa vez -, mas Copérnico e Tycho Brahe, sob os quais ele desenvolveu seu trabalho e sua vida. Várias vezes replicava, aos que esperavam e exigiam dele previsões astrológicas, que o imperador não o havia nomeado para ser o áugure oficial, publicus vates, mas sim para levar adiante a ciência da astronomia, a qual havia perdido seu autêntico mestre, Tycho Brahe. Kepler redigiu um breve escrito em alemão que apresenta em seu título uma espécie de defesa da astrologia: “Tertius interveniens. ${ }^{18}$ Isto é um aviso para alguns teólogos, médicos e filósofos (...) que em sua condenação barata da superstição astrológica, não joguem a criança junto com a água do banho, e com isso, insipientemente repugnem sua profissão" (Kepler, 1858, p. 547). Mas, mesmo nesse escrito de defesa, redigido em função de propósitos práticos, encontra-se a mais clara e mais aguda rejeição do valor teórico e científico da astrologia:

Essa astrologia é como uma filhinha tola (...), mas, meu Deus, onde sua mãe, a muito sensata astronomia, estaria se ela não tivesse sua filha tola. Afinal, o mundo é ainda mais tolo, tão tolo que a astronomia, essa velha e prudente mãe, tem que mentir e falar de coisas em virtude das tolices de sua filha (idem, p. 560).

Só podia falar assim um pensador que em seu ser espiritual sempre se agigantou diante da astrologia, ainda que em sua vida e em seu destino estivesse ligado a ela; um pensador que rompeu com o domínio da magia, cuja interdição sobre a vida intelectual perdurou por milênios, e que alcançou a plena liberdade de uma nova mente científica.

16 Rudolf II (1552-1612), imperador do Sacro-Império entre 1576 e 1612. (Nota do Tradutor)

17 No original, Nativität. Significa no contexto do século XVI o momento exato do nascimento e o mapeamento do destino e do auspício por meio da previsão astrológica. Cf. (Grimm \& Grimm, 1854-1961). (Nota do Tradutor)

18 Ou As intervenções de terceiros. Trata-se de obra publicada por Kepler em 1610. (Nota do Tradutor) 


\section{Referências}

Goethe, J. W. (1893a). Zur Farbenlehre: historischer Theil. Weimar: Böhlau. (Weimarer Ausgabe 2, III)

Goethe, J. W. (1893b). Zur Naturwissenschaft. Weimar: Böhlau. (Weimarer Ausgabe $2, \mathrm{XI})$

Goethe, J. W. (2011) Fausto I. São Paulo: Editora 34.

Grimm, J.; Grimm, W. (1854-1961). Deutsches Wörterbuch. 16 vols. [Versão digital]. Recuperado de: http://woerterbuchnetz.de/cgi-bin/WBNetz/wbgui_ py?sigle=DWB. Acesso em: 17 jun. 2020.

Kant, I. (1781). Kritik der reinen Vernunft. Berlin: Bruno Cassirer, 1913. (Werke in Gemeinschaft mit Hermann Cohen III)

Kepler, J. (1858). Opera omnia. vol. 1. Frankfurt am Main: Erlangae.

Kepler, J. (1859). Opera omnia. vol. 2. Frankfurt am Main: Erlangae.

Kepler, J. (1860). Opera omnia. vol. 3. Frankfurt am Main: Erlangae.

Recebido em: 10.02 .2020

Aceito em: 07.05.2020 